\title{
A FORMAÇÃO CONTINUADA COMO CONDIÇÃO PARA A MELHORIA DO TRABALHO DO DOCENTE COM DESENVOLVIMENTO DA PESQUISA E INOVAÇÃO NO ÂMBITO DAS NOVAS TECNOLOGIAS NA EDUCAÇÃO
}

\author{
Marcilene Zerbone Zucolotto*
}

\section{RESUMO}

Este artigo propõe uma reflexão sobre a necessidade de formação continuada para o docente brasileiro como forma de melhoria de seu trabalho pedagógico e educacional na atualidade dominada pelas tecnologias modernas. Em geral, os cursos superiores de pedagogia e outros correlatos formam deficientemente o profissional e este necessita se aperfeiçoar continuamente para poder lidar com os desafios da presença das tecnologias informáticas. O objetivo desta pesquisa é investigar como a formação continuada contribui para compensar essa insuficiente situação acadêmica do docente. Com complementação do hábito de pesquisa e de adoção da inovação, o docente poderá ensinar qualitativamente empregando as novas tecnologias comunicativas em sala de aula. A metodologia se embasa em abordagem bibliográfica com consulta de vários autores especialistas em docência e em tecnologias na educação, que trazem informações importantes para a qualidade do ensino e melhoria da aprendizagem para o discente. $O$ docente precisa ser pesquisador e adotar posturas inovadoras para continuar desenvolvendo habilidades e técnicas com o uso das tecnologias digitais em sala de aula.

Palavras-chave: Formação continuada. Tecnologias digitais. Pesquisa. Inovação.

\footnotetext{
* Mestre em Ciências da Educação pela Facultad Interamericana de Ciencias Sociales. Asunción-PY. Contatos: E-mail: marcilenez@hotmail.com Tel: (27) 99921-4357.
} 


\section{INTRODUÇÃO}

A formação do docente brasileiro nos últimos tempos vem sofrendo um desafio sem precedentes: de ser atualizado continuamente devido à onipresença das tecnologias digitais de informação. Esse profissional, por outro lado, tem recebido atenção dos governos para se manter qualificado para esses novos tempos desafiadores; no entanto, muitos dos cursos tradicionais de pedagogia ainda 0 formam não suficientemente, a tal ponto que se constata que ele não consegue acompanhar as rápidas transformações tecnológicas e necessita de continuar se aperfeiçoando para poder ministrar seu trabalho e aulas em escolas.

O docente como agente mediador no processo educacional precisa incorporar as ferramentas tecnológicas no processo de ensino e aprendizagem, buscando ter formação continuada. A escola e os governos, cientes dessa necessidade, precisam auxiliar na melhoria profissional dele, pois a informática na educação e o uso crescente de aparelhos móveis conectados à internet exigem que haja domínio e atualização constante. Muitas vezes, deve o próprio docente buscar melhorar sua formação e se conscientizar de que necessita disso.

O objetivo desta pesquisa é investigar como a formação continuada contribui para compensar essa insuficiente situação acadêmica do docente. Outros objetivos enfocam sobre a necessidade de pesquisa qualitativa e adoção de posturas de inovação, que se traduzem em investir em cursos profissionalizantes, atualização contínua e construção de atividades e projetos que estimulem a inventividade e habilidades dos discentes.

Este artigo segue constituído de uma metodologia de pesquisa bibliográfica destacando autores que trazem informações sobre formação docente e utilização de modernas tecnologias na escola. Busca-se informar sobre as transformações que as tecnologias promovem na humanidade e na escola; a seguir, são apresentados os problemas de formação do docente e as contribuições da formação continuada, da pesquisa e da inovação. 


\section{FUNDAMENTAÇÃO TEÓRICA}

O século XXI se inicia sob a égide das conquistas tecnológicas realizadas pelo homem, que começaram há milênios, pois a humanidade sempre se beneficiou com as tecnologias que produzia, seja desde para plantar e colher grandes quantidades de alimento seja quanto para montar grandes fábricas. As tecnologias sempre foram associadas e atreladas ao desenvolvimento econômico e, portanto, para a obtenção de riquezas e consequentemente de dominação de vastas regiões da Terra pelos detentores de grandes recursos econômicos.

De acordo com o sociólogo clássico Weber (1999), o homem se constitui em um ser ambicioso por natureza, pois sua constituição corporal exige constante satisfação de suas necessidades básicas para sobreviver e ainda possui habilidades cerebrais que precisam de ser satisfeitas praticamente todo o tempo de vida. Por isso, ele aprendeu a utilizar os elementos naturais para satisfazer suas sobrevivências e necessitou desenvolver outras técnicas capazes de aumentar a sua satisfação e exploração pelo mundo onde vivia.

Ainda de acordo com Weber (1999) o ser humano, aprendendo a utilizar as tecnologias que inventava, passou a dominar as plantas e os animais e extrair da terra as matérias-primas para produzir seus instrumentos de coleta e habitações. Á proporção em que descobria mais inovações tecnológicas, ele passou a inventar outras novas tecnologias aperfeiçoadas, que melhoravam as anteriores e o possibilitavam a expandir-se para além de seus limites.

Atualmente, parte da humanidade já usufrui os benefícios dos antigos avanços tecnológicos, que promoveram desde o aparecimento de várias nações quanto ao progresso promovido pela economia globalizada.

Atualmente está se iniciando a chamada quarta revolução industrial no mundo, onde se registra a onipresença da informática, uma das maiores conquistas das tecnologias modernas. Antes do término do século anterior, houve um salto tecnológico sem precedentes na história humana com a invenção e comercialização de computadores e demais aparelhos midiáticos avançados, como os smartphones, que possibilitam o rápido processamento de dados e transmissão simultânea de imagens e textos via internet.

A internet é também produto dessa inovação oriunda da informática, que 
tornou-se um elemento imprescindível pela modernização da sociedade e da economia mundial, além de promover encontro de várias pessoas e divulgação do conhecimento.

Como informa Araújo (2009), a internet se popularizou devido a muitas inovações tecnológicas recentes, que permitiram o desenvolvimento de máquinas capazes de armazenar grandes quantidades de dados e de realizar outras funções importantes. Foi tão forte o avanço dessa tecnologia que a mesma acabou adentrando no contexto escolar, pois muitos estudiosos a viram como ferramenta importante para a aprendizagem e a transformação do conhecimento dos discentes e de demais pessoas.

Guimarães; Ribeiro (2011) informam que as tecnologias são um produto da inventividade humana, pois correspondem ao resultado da busca da praticidade imediata. A ciência é responsável pela existência das tecnologias de informação que a humanidade está dispondo atualmente. Assim, a ciência e a tecnologia são objetivadas para a melhoria de vida e do modo de ser da sociedade em quaisquer áreas.

Os recentes meios de comunicação que empregam recursos de informática, como os smartphones e os tabletes, por sua portabilidade e praticidade, estão cada vez mais sendo utilizados para diversas atividades humanas, em especial para a educação. A internet passa a ser uma ferramenta que conecta pessoas e informações e pode ser acessada através desses aparelhos ou outras mídias informáticas. Ainda segundo Guimarães; Ribeiro (2011), essas mídias constituem um suporte de difusão da informação, que se constitui em um meio intermediário de expressão capaz de transmitir mensagens, ao mesmo tempo em que permite que o usuário as manipule diretamente.

A informática permite a interatividade entre usuário e os websites da internet e também com as mídias digitais, que contêm comandos e outros recursos que possibilitam essa interação e a troca de informações. Os aplicativos são um dos produtos de interatividade que a internet permite aos seus usuários e têm especificações próprias para cada funcionalidade.

Destacam-se entre os aplicativos mais populares aqueles que integram as redes sociais, canais especiais da internet que permitem uma gama de operações de mensagens e interatividades simultâneas entre usuários. Nas redes sociais, de acordo com Coutinho (2019), dentre esses aplicativos destacam-se o Facebook e o 
WhatsApp, que permitem a realização de várias funções, como leitura de livro digital, acompanhamento de conta bancária, atualização de informações jornalísticas ou de bate-papo, troca de mensagens, agendamento de eventos, exibição de vídeos de trailers de filmes em lançamento, e muito mais.

$\mathrm{Na}$ escola, a informática se tornou um instrumento que promove a pluralidade de ideias e informações, assim como novos modos de relacionamento entre pessoas e máquinas, além de fomentar a inter-relação e intercâmbio crítico. As escolas precisaram se adaptar a essa nova realidade, pois necessitaram incluir em seu espaço físico unidades especiais para a acomodação de máquinas de informática, os chamados laboratórios.

A informática na escola recebeu o nome de tecnologia da informação e comunicação (TIC) e esta se define, no contexto escolar, como um conjunto de recursos que proporcionam a automação e/ou a comunicação nos processos existentes no ensino, favorecendo a pesquisa científica e outras atividades que aperfeiçoam a aprendizagem.

Zavam (2009) observa que as novas tecnologias na educação criaram um novo cenário, em que predominam novas formas de remodelagem de processamento de saberes em praticamente nos espaços virtuais.

Esses espaços engendram uma cultura virtual, em que os sujeitos da integração podem ocupar distintos espaços em sincronia, sem haver necessidade de estar fisicamente contatados entre eles a cultura virtual dá, assim, forma a uma nova realidade social (ZAVAM, 2009).

As tecnologias informáticas constituem produto da fragmentação e da dicotomização do conhecimento, que resulta tanto da especialidade quanto do processo educacional. A educação formal foi sendo desdobrada em várias outras formas de se ensinar e aprender. $O$ antigo modo de ensino - o tradicional e mecanicista - foi sendo substituído por não mais responder aos novos avanços e desafios (POMBO, 2019).

Os docentes também foram afetados pela tecnologia computacional e tiveram que se adaptar a isso, mesmo que apresentem em menor ou maior grau uma resistência quanto à sua utilização como elemento pedagógico que promove aprendizagem.

Souza (2009) salienta que as tecnologias modernas causam diversas reações positivas e até mesmo negativas entre os docentes, visto que os mesmos foram 
educados em sua formação a repassar conhecimentos acadêmicos tradicionais aos discentes e não têm preparo suficiente para lidar com novos desafios e competências. Some-se a isso que o processo educacional se tornou mais fragmentário e essa característica se aprofunda cada vez mais agora com as tecnologias modernas móveis, como os computadores, tabletes e smartphones.

A formação dos docentes também foi afetada e necessita ser reavaliada para se adaptar às novas realidades, conforme observa Zavam (2009).

Cardoso; Azevedo; Martins (2019) aponta que o domínio das novas tecnologias da informação constitui direito básico à liberdade e expressão e também são ferramentas que contribuem para o desenvolvimento social, econômico, cultural e intelectual. As tecnologias que vão surgindo contribuem para se aumentar debates sobre seu uso na educação. Isso ocorre porque os novos discentes já entram nas escolas dominando saberes pré-escolares como contar, ouvir histórias e realizar tarefas como escrever. As novas tecnologias que eles já utilizam em casa, como a internet e mais recentemente o telefone celular com conexão online, contribuem para fazer revisões sobre o uso delas na educação.

Como bem explica Almeida (2003), os avanços tecnológicos contribuem para acelerar processos e aperfeiçoar programas; cada avanço na telecomunicação ocorre provocação de mudanças de comportamento e percepção das pessoas perante o mundo à sua volta e isso faz com que várias instituições, em especial às escolas, se adaptem para poder educar os novos discentes nos tempos atuais.

Os docentes são também desafiados a se adaptar às novas tecnologias para continuar trabalhando e aperfeiçoando o seu conhecimento. As Diretrizes Curriculares Nacionais da Educação Básica dão destaque a isso quando informam que, como qualquer outra ferramenta, as tecnologias devem ser utilizadas e adaptadas para diversos fins educacionais de forma a possibilitar que a interatividade virtual se desenvolva de forma mais intensa e prazerosa. As tecnologias jamais deverão substituir o docente e as outras formas tradicionais de conhecimento educacional.

Os docentes, segundo Carvalho (2004) necessitam assumir-se de quatro características para ser moderno e receptivo das tecnologias modernas: ser competente; ser reflexivo; ser orgânico-crítico; e pós-crítico.

Revestindo-se de competência, o docente se torna capaz de assumir novas formas de pensar e proceder didaticamente sem receios e ter segurança necessária 
para continuar oferecendo suas aulas para os discentes, com conexão às novas realidades. Ao ser reflexivo, ele promoverá encontro entre teoria e prática de forma contextualizada com as modernas tecnologias, percebendo-se também como um orientador nesse processo. E, por finalização dessa observação, o docente sempre deve assumir uma postura crítica nesse contexto para poder discernir em suas escolhas.

A educação brasileira conhece há poucas décadas a informática em seu bojo, sendo fruto de esforços de inúmeros autores que implantaram novas formas de educar para se adquirir novas habilidades e competências para o mundo atual, regido pelas transformações rápidas e impactantes. As novas tecnologias de informação na escola promovem o encontro entre a tradicional e as novas abordagens educacionais. Chiavatta (2006), contudo, informa que a escola em geral não consegue acompanhar a velocidade das mudanças tecnológicas e necessita ser auxiliada nesse contexto.

Tedesco (2004) diz que antes do computador e do smartphone entrarem na escola, a televisão e seus assessórios, como o videocassete e a caixa de som, por exemplo, iniciaram a entrada dessa instituição para o mundo dominado pela tecnologia, de forma a facilitar o aprendizado e incorporando valores e novidades que o mundo já estava vivenciando.

As tecnologias promovem uma agilidade de buscas de informações e pesquisas a quaisquer tempos e lugares. Os smartphones, produtos da primeira década deste novo milênio, se popularizaram porque incluíram a internet e se tornaram cada vez mais populares e possibilitavam vendas em grande quantidade de aparelhos eletrônicos a uma velocidade nunca antes vista (TEDESCO, 2004).

Todas as mídias telecomunicativas são importantes para a educação atual e contribuem para a expansão do conhecimento e da aquisição de habilidades e competências. Como bem diz Rojo (2012) o computador, o telefone celular e a televisão cada vez mais se distanciam de uma máquina de reprodução e se tornam uma produção colaborativa. Assim, a utilização de máquinas multimídias acaba provocando maior interatividade entre elas e seus usuários e estes precisam de saberes e técnicas para poder utilizá-las adequadamente.

No Brasil, as novas tecnologias de informação nas escolas são regulamentadas pela Lei de Diretrizes e Bases da Educação (LBD, Lei n. 9.394/96) quando trata de educação profissional e tecnológica. As Diretrizes Curriculares da 
Educação Nacional informam que as novas tecnologias de informação devem fazer parte do currículo escolar como área transversal, que possibilite favorecer as atividades escolares e fomentar estratégias, competências e habilidades nos discentes.

As tecnologias digitais com conexão à internet são importantes para todas as disciplinas, pois promovem pesquisas mais rápidas e atualizadas. Destacam-se os aplicativos como produtos que facilitam a prática educacional.

\section{A PROBLEMÁTICA FORMAÇÃO DOS DOCENTES}

A formação dos docentes, em quaisquer áreas do conhecimento acadêmico e pedagógico, constitui uma grande complexidade nos tempos atuais, pois as rápidas transformações promovidas pelas novas tecnologias e demais mudanças de paradigmas educacionais forçaram novas posturas frente às novas necessidades de aprender e como processar o conhecimento.

Cortelazzo (2010) utiliza a expressão suportes tecnológicos na comunicação social como um modo de classificar os meios comunicativos por meios das mídias digitais, tanto móveis quanto imóveis fisicamente. A linguagem verbal escrita, nessa nova modalidade, se torna a mais importante forma de conhecimento devido que se constitui na primeira linguagem utilizada que permite que o usuário se conecte com as informações digitais e possa realizar intervenções diversas.

Antes de adquirir competências com as modernas tecnologias, o docente, em sua formação, necessita acercar-se de pesquisa científica e deve processá-la em seu trabalho profissional. Rodrigues (2009) salienta que a produção científica na formação dos docentes ainda se encontra incipiente, isso porque as entidades superiores privilegiam antigos procedimentos educacionais, que encontram-se desconectadas com a realidade do mundo moderno, mas concatenada com os interesses acadêmicos tradicionais.

Os currículos, segundo Menezes (2009), precisam ser construídos na esfera em que contemplem seus atores sociais, atendendo à formação básica do processo de ensino-aprendizagem e à formação dos docentes. Ainda segundo a autora, as práticas educativas devem estar coerentes com o contexto escolar e social da atualidade, devendo também ser uma reflexão crítica sobre os discursos, os 
conteúdos escolares e, as relações, os diferentes aspectos do cotidiano escolar e, em particular, sobre a educação dos discentes.

A constituição de um currículo, conectado com as realidades presentes da atualidade, leva o docente a planejar melhor suas aulas e adaptar-se às novidades tecnológicas, sem perder o foco e as necessidades futuras que ainda irão ocorrer. Infelizmente, como afirma Menezes (2009), muitos docentes ainda são resistentes às mudanças e se recusam a ensinar no ambiente novo das tecnologias, porque o currículo escolar ainda se restringe a programas de conteúdos das disciplinas, metodologias e estratégias já consolidadas.

Não aceitando integralmente o novo currículo, também o docente rejeita as determinações da nova LDB, que prevê "proposições de gratuidade e obrigatoriedade, cidadania, autonomia, qualidade de ensino e inclusão [...]" (MENEZES, 2009, p. 205).

Tardif (2002) também constata que a formação dos docentes, em quaisquer áreas do conhecimento, se reduz a saberes restritos e independentes de outras disciplinas ministradas, isso porque os cursos superiores de pedagogia e de outras áreas correlatas encontram-se também atrelados às antigas visões educacionais, que persistem ainda no academismo brasileiro, o que força os currículos a também espelhar essa especialização.

Ainda informa Tardif (2009, p. 41): "Além de não controlarem nem a definição nem a seleção dos saberes curriculares e disciplinares, os docentes não controlam nem a definição nem a seleção dos saberes pedagógicos transmitidos pelas instituições de formação." O autor que a formação do docente é crítica e complementa que os cursos superiores "assumem as tarefas de produção e de legitimação dos saberes científicos e pedagógicos, ao passo que aos docentes compete apropriar-se desses saberes, no decorrer de sua formação [...]" (TARDIF, 2009, p. 41).

Diante dessa constatação, a formação do educador permanece problemática, já que os currículos também ficam atrelados com velhos paradigmas educacionais que impõem limitações ou pequenas adaptações para o novo.

Volta-se novamente para o docente: é ele quem precisa se aperfeiçoar para continuar ensinando com o novo para poder educar seu discente. Ele necessita verse problemático e carente de boa formação para poder buscar novas formas de 
atualização e até mesmo cursos modernos que the ensinem a ministrar conteúdos atualizados utilizando novas tecnologias e recursos para ensinar em sala de aula.

\section{A NECESSIDADE DE FORMAÇÃO CONTINUADA COM PESQUISA E INOVAÇÃO PARA O DOCENTE}

Um dos primeiros passos para a superação dos problemas de sua formação, o docente precisa adotar uma postura crítico-reprodutivista, nos dizeres de Saviani (1989). Isso implica que o profissional necessita criticar a atual conjuntura educacional brasileira, ainda visada a formar indivíduos que acumulam saber sem poder aplicá-lo em sua vida profissional futura e nem respondem aos novos desafios. Com a inserção cada vez mais atuante das novas tecnologias informáticas, e com a renovação também constante das mesmas com o passar dos anos, é imperioso que o docente precise tentar modificar ou minimizar o poder da atual conjuntura escolar para que haja liberdade de produção realmente científica na escola.

Suhr (2011) declara que a crítica contra o reprodutivismo, alimentada durante muitos anos pelo tecnicismo e pelo construtivismo, é necessária para revisar os conteúdos escolares e contribuir para a superação de problemas tradicionais da educação, como o acúmulo de disciplinas e de conteúdo das mesmas para os discentes.

Contudo, para realizar essas posturas críticas, o docente necessita estar amparado por leis nacionais para poder realizar essas tarefas. De fato, a nova lei de diretrizes e bases da educação nacional (LDB) já prevê que a formação moderna e atualizada dos docentes em cursos superiores de pedagogia e outras áreas correlatas deve priorizar um consistente rearranjo profissional que vise capacitá-lo a lidar com as novas tecnologias e novos currículos (BRASIL, 2017).

No tocante a esse ponto, Brzezinski (2003) informa que a formação qualitativa do docente ainda está distante da realidade do que é ideal para a educação dos jovens, pois, embora o Decreto Presidencial de 3276/99 busque melhorar a formação acadêmica, as disposições ainda estão distantes dos ideais emancipatórios e modernizantes que propõem_as novas tecnologias de informação. 
Aguiar (2003) informa que os cursos superiores devem investir em educação continuada para superar os problemas de formação do docente no meio acadêmico tradicional. Isso a nova LDB ampara, pois os cursos superiores têm que formar profissionais para a educação básica com programas modernos e atualizados, que acompanhem o mundo em transformação, para que o discente se sinta bem em ser educado em uma instituição escolar concatenada com a sua realidade.

Por isso, ao introduzir novas tecnologias e abordagens na escola há quase sempre resistências por parte dos docentes e das equipes pedagógicas. As teorias caracterizam o docente como um mero orientador e divulgador de saberes. A marginalidade dominou os currículos de formação do docente e este se viu como um reprodutor das tecnicidades. A pedagogia tecnicista considera o marginalizado, tanto o docente quanto o discente, como incompetentes, ineficientes e improdutivos. O objetivo dessa pedagogia é formar indivíduos eficientes, capazes de executarem todo tipo de atividades para aumentar a produtividade e consequente lucratividade de empresas e outros serviços do sistema capitalista de produção (PEREZ, 2005).

As novas tecnologias na educação, como bem salienta Saviani (1999), têm que, em primeiro lugar, emancipar o indivíduo dotando de competências e habilidades e não reduzindo-o a quase um autômato; para o docente, elas precisam dinamizar suas condutas pedagógicas e se tornar um elemento importante para a aprendizagem e aperfeiçoamento contínuos.

A formação continuada do docente contrabalancearia a precariedade da formação desempenhada pelas instituições superiores de ensino, além de se tornar praticamente a única forma de atualização e profissionalização do mesmo. Mesmo assim, diminuiria o poder decisório das universidades por essa nova modalidade de formação.

Demo (1998) propõe, além de formação continuada, a pesquisa contínua e qualitativa como atitude que aperfeiçoa o docente, na medida em que este, com seus questionamentos, possa a modificar as posturas vigentes no academicismo e na educação escolar.

De igual parecer estão Kronbauer; Simionato (2008), que informam como uma das soluções para o problema da formação do docente seja a produção intensa da pesquisa. É o docente quem precisa perceber-se como profissional que tem engajamento insuficiente para tomar a atitude de mudança, de querer superar suas 
limitações com a vontade de pesquisar, de buscar o novo e com isso poder ensinar melhor aos seus discentes.

A ruptura paradigmática com as velhas proposições educacionais, estas marcadas pelo tecnicismo e pelo construtivismo, deve ser realizada para que haja adoção de técnicas e métodos de ensino mais eficientes, que promovam maior encontro entre teorias e práticas educacionais.

Melo (2011) informa que as tradicionais práticas educacionais refletem a influência do modo de produção do capitalismo globalizado, ou seja, os discentes são educados e preparados para serem melhores profissionais que o mercado quer; os docentes são formados para serem orientadores quase perfeitos nesse processo, pois devem conhecer em pormenores como funcionam todas as estruturas de produção e repassar isso aos seus discentes, de modo que também estes sejam reprodutores dinâmicos das cadeias produtivas.

O docente tão somente não deve ser visto como uma máquina, um repositório das tendências do mundo moderno, mas também deve imbuir-se de sensibilidade, de comprometimento com a ética e com a igualdade social, tão caras para os regimes democráticos.

A educação escolarizada, nos dizeres de Melo (2011, p. 202), deve afastar-se da "repetição, nos conhecimentos tácitos e na imitação como forma de aprendizado" para se tornar um importante elemento de promoção de pessoas. As novas tecnologias telecomunicativas permitem romper essa mecanicidade da educação, pois representam a modernidade, a inventividade e a inovação de conteúdos quase que continuamente. A internet rompe com as limitações das concepções capitalistas arcaicas, permitindo às pessoas maior conhecimento e percepção do mundo.

Diante desse quadro, 0 docente tem que se perceber como agente transformador para compensar sua formação acadêmica um pouco limitada e atualizar-se continuamente para poder oferecer aos seus discentes oportunidades de desenvolvimento pessoal com a utilização adequada e racional das tecnologias telecomunicativas disponíveis.

Kronbauer; Simionato (2008) defendem também que o educador também deve desenvolver competências nesse novo espaço contemporâneo para poder responder rapidamente aos problemas de preparação dos discentes ao futuro. Essas competências respaldam-se no fundamento propedêutico e científico, ou seja, se caracterizam por promover domínio de conhecimentos mais elevados e voltados 
para a produção científica dos conteúdos, como forma de desenvolvimento do raciocínio e da inventividade.

Ainda segundo Kronbauer; Simionato (2008), os docentes-pesquisadores devem desenvolver as seguintes dimensões de aprendizagem: a) propor situações em que o sujeito precisa pensar, comparar, argumentar, analisar, descobrir e realizar outras ações articular conhecimentos já construídos para novos desafios; b) desenvolver a área afetivo-emocional, em que se conduz o sujeito ao conhecimento de suas capacidades e limitações no convívio com as pessoas com os quais fomentará a ética e o senso de solidariedade; c) buscar analisar propostas de articulação dos conhecimentos construídos com as situações concretas do dia a dia, sempre procurando desafiar o discente à comunicação e à tomar decisões diante de situações desafiadoras; e d) desenvolver valores éticos, políticos e sociais em uma dimensão de valorização do conhecimento.

Ao realizar essas ações, o docente terá capacidade de transformar o ensino em uma rede de oportunidades, se o mesmo se propuser a si mesmo querer promover a inovação de seus valores e visões já inseridos em sua formação.

Demo (1999) salienta também que o docente, para ser transformador da realidade educacional, deve desenvolver hábitos para a pesquisa, como condicionante imprescindível para a melhoria da aprendizagem. O autor informa que 0 ato de pesquisar leva o docente a se qualificar-se continuamente e se preparar para os desafios que surgem no contexto de sua vida; assim, ao realizar esse procedimento, ele terá condições de praticamente falar a língua do discente e propor novos desafios que vão contribuir para a melhoria da aprendizagem.

A ação de pesquisar complementa a formação continuada do docente. Já Vygotsky (2003) defendia que a relação que o homem com o mundo é uma relação mediada, em que trocas entre esses dois elementos são componentes importantes para a dinamização do conhecimento. A mediação possibilita consolidar que as funções psicológicas superiores se consolidem. Ainda segundo o autor, o processo de construção do conhecimento ocorre em uma complexa dinâmica interativa, da qual participam três elementos essenciais: o discente, como sujeito do conhecimento; os conteúdos e os significados; e o docente que atua como mediador.

O docente, se assumindo como pesquisador, formador de si mesmo e mediador, conseguirá atingir vários objetivos educacionais previstos na nova LDB e 
em outras normas e pensamentos proferidos por diversos autores educacionais. Não é uma tarefa fácil de se alcançar, visto que o sistema educacional brasileiro ainda valoriza a formação sistemática do profissional.

A escola brasileira também encontra-se carente de inovação e renovação de suas funções nesse novo tempo marcado pelo avanço contínuo das tecnologias e a mesma precisa se atualizar continuamente para poder educar e formar o discente para esses novos desafios.

Giroux (1997) declara que as novas tecnologias têm que tentar superar a separação de concepção de execução das atividades escolares, a padronização do conhecimento escolar com o interesse de administrá-lo e controlá-lo e a desvalorização do trabalho crítico e intelectual de docentes e discentes.

O discente, quase sempre, como informa Arroyo (2000) não possui condições de percorrer sozinho o caminho do aprendizado, por isso, a intervenção do docente e quando possível de outros alunos, é fundamental para a promoção do indivíduo e apropriação do conhecimento. As novas tecnologias na educação devem realizar a percepção de Vygostsky (2003), pois constituem o objeto que serve de mediação do conhecimento. Com isso, o docente precisa se tornar um intelectual transformador, necessitando antes de uma boa formação pedagógica já amparada pelas modernas tecnologias, que o possibilitem a ministrar aulas com eficiência e segurança, com objetivos e projetos bem delineados.

Para completar sobre a formação continuada do docente é necessário que o mesmo assuma a execução da inovação, como componente imprescindível para poder conectar-se com a realidade e poder auxiliar os seus discentes.

A inovação, de acordo com Hernandez et al. (2000), se caracteriza em um conjunto de posturas que levam para a melhoria contínua das atividades ou estado existentes, de forma a beneficiar vários autores envolvidos com o processo. Muitos países desenvolvidos já adotaram a educação inovadora como uma nova modalidade de se ensinar empregando as mais modernas tecnologias e/ou processos educativos mais adaptados à realidade atual.

O termo inovação surge primeiramente no mundo corporativo como parte do processo de desenvolvimento e aperfeiçoamento das atividades industriais e comerciais. De acordo com Messina (2001), esse elemento se inicia a partir da década de 1950 nos países desenvolvidos ocidentais, onde vários profissionais a concebiam no âmbito da produtividade industrial como um processo que se realiza 
em etapas previsíveis, buscando-se o aperfeiçoamento do objeto material para o mercado consumidor. Também valia para os serviços, pois quanto mais qualidade tiver com inovação, com criatividade, mais a empresa atrairia consumidores e, com isso, aumentaria seu faturamento e porventura seu crescimento.

Gomez (2007) destaca que também a escola deve adotar as posturas da inovação para poder ser moderna e atualizada, promovendo a melhoria da educação para sua clientela, os discentes. Ainda segundo o autor, a inovação na educação deve estar calcada na ciência e na tecnologia e ambos os elementos devem ser trabalhados em praticamente todas as disciplinas para que as mesmas possam ter significado para a pessoa e proporcionar condições teóricas e práticas para a vida profissional.

Deve a inovaçãoestar vinculada com algum processo de reforma educacional, pois deve ser testada e aprovada para fazer parte do currículo escolar. De fato, muitas das prerrogativas legais das principais legislações educacionais brasileiras já prestigiam a aplicabilidade de recursos modernos que melhoram a educação escolar.

Hernandez et al. (2000) informa que há muitas características que favorecem a implementação da inovação no âmbito escolar, a começar pela necessidade de mudança para minimizar ou eliminar a persistência de problemas que acometem o rendimento escolar. A inovação pode ser pensada e utilizada como uma ferramenta importante para o desenvolvimento da pesquisa em sala de aula, de modo a favorecer tanto para o discente quanto para o docente a busca por novas formas de obtenção e manipulação do conhecimento. Para o autor, o processo de realização da inovação apresenta duas formas básicas: uma executada fora do planejado pelos especialistas, condizente com a interpretação ou aos interesses dos usuários, neste caso, a escola; e outra resultante de uma negociação entre os promovedores inovadores e os docentes.

Os docentes necessitam de ser assessorados pelos promovedores inovadores - estes podendo ser palestrantes ou até mesmo profissionais integrantes da equipe escolar - para poderem desenvolver suas capacidades de inovação em sala de aula.

Sendo inovadores, os docentes podem dar ênfase no ensino de procedimentos, que serão úteis para desenvolver novas práticas em sala de aula. Além disso, ao assumir-se inovador, o docente necessita de atualização permanente 
para poder lidar com as novas tecnologias que surge. Isso implica também que os mesmos precisam investir em cursos de capacitação e aprender a utilizar a internet para estudar continuamente. A escola deve promover a inovação para também ser moderna e proporcionar aos discentes um ambiente propício de fecundas aprendizagens.

De semelhante opinião são de Lublik; Petraits; Lublik (2011) que propõem que a educação formal deve realmente ser inovadora, permitindo que a pesquisa tenha, no seio da educação, a função de construir e adensar os conhecimentos, além de auxiliar na construção de competências e habilidades que os futuros profissionais irão desempenhar na sociedade moderna.

A inovação constitui também um dos elementos que auxiliam na formação profissional do docente, pois permite que o mesmo se abra para as novidades e sinta a vontade de participar desse mundo em perpétua modificação e aperfeiçoamento. Como os cursos superiores de formação, em sua maior parte, não são inovadores e nem estimulam os seus acadêmicos a superar suas limitações das práticas pedagógicas, cabe aos docentes buscarem a inovação ao investir em novos cursos capacitadores, que Ihes vão oferecer condições para lidar com as novas gerações de discentes e as respectivas tecnologias que eles atualmente utilizam.

Hernandez et al. (2000) informam ainda que a inovação na escola traz uma série de benefícios, a começar pela qualificação do trabalho do docente e do aperfeiçoamento do currículo escolar, que deve estar condizente com as normas legais da educação brasileira e com os avanços tecnológicos. Não há uma estrutura pronta de como é a inovação escolar, a mesma deve ser um conjunto organizado de ações que visem a melhoria do ensino; é um projeto em transformação contínua.

Adotando a inovação, o docente pode definir melhor seus objetivos pedagógicos e desenvolver projetos que possibilitam que os discentes, sob quaisquer graus de dificuldades e situações, possam sentir-se assessorados e participar ativamente em praticamente todas as atividades escolares. A inovação estimula a criatividade, a vontade de participar e propicia o reconhecimento da diversidade existente em sala de aula.

Introduzir uma inovação no âmbito da educação implica, antes de tudo, uma mudança de velhas práticas educativas; assim, constitui-se em um compromisso de assumir atitudes que visem a melhoria de todas as atividades escolares, do aperfeiçoamento do currículo e de flexibilidade do conhecimento, que deverá ser 
cada vez mais transversal e multifocado em competências e habilidades. A inovação deve ser concebida ou entendida como a busca de respostas aos desafios presentes na dinâmica dos processos escolares, que deve ser realiza em conjunto com todos os atores educacionais.

\section{CONCLUSÃO}

A abordagem sobre formação continuada do docente revelou que a educação brasileira, em especial a pública, tem um enorme desafio para responder às necessidades que impõem as modernas tecnologias de informação, tais como atualização contínua, melhoria da percepção do mundo, aquisição de novas habilidades para operar máquinas cada vez mais automatizadas e inteligentes, entre outras.

Em geral, o docente brasileiro possui formação que não contempla a modernização da educação, nem o capacita para enfrentar os desafios lançados pelas tecnologias digitais informativas. Para superar esses problemas, ele precisa, antes de tudo, se conscientizar de que necessita se aperfeiçoar para poder educar seus discentes e atender às exigências das modernas legislações educacionais. A solução é a formação continuada, que o capacita a melhorar sua bagagem profissional e ainda o prepara a interagir com os equipamentos no sentido de qualificar o conhecimento para fim de obter um resultado satisfatório em seus planejamentos em sala de aula.

Esta pesquisa propôs-se a abordar sobre a necessidade de formação continuada para o docente como objeto importante que melhorará seu trabalho pedagógico. Contudo, sem a pesquisa e a inovação, ele não poderá completar essa qualificação de suas atividades. A pesquisa impõe capacitá-lo a atualização permanente, enquanto que a inovação o faz se envolver com a modernização do currículo escolar e ser mais inventivo e estimulador do conhecimento. Ao adotar essas posturas, o docente contribuirá para a superação de velhos problemas pedagógicos e terá mais condições de auxiliar na construção do futuro do discente. 


\section{REFERÊNCIAS}

ARAÚJO, Julio C. Internet \& Ensino: Novos gêneros, outros desafios. 2 ed. In: RODRIGUES-JUNIOR, Adail S. (org.). Internet e Ensino: Novos gêneros, outros desafios. Rio de Janeiro: Singular, 2009.

ARROYO, M. G. Ofício de mestre: imagens e autoimagens. Petrópolis, Rio de Janeiro: Vozes, 2000.

BRASIL. LDB - Lei de diretrizes e bases da educação nacional. Brasília: Senado Federal, 2017.

BRZEZINSKI, Iria (org.) LDB Interpretada: diversos olhares se entrecruzam. 8 ed. São Paulo: Cortez, 2003.

CARDOSO, Amanda; AZEVEDO, Juliana F.; MARTINS, Ronei X. Histórico e tendências de aplicação das tecnologias no sistema educacional brasileiro.

Disponível em:

http://pead.ucpel.tche.br/revistas/index.php/colabora/article/viewFile/252/179. Acesso em: 5 jan. 2019.

CARVALHO, Janete M (org.). Diferentes perspectivas da formação docente na atualidade. Vitória: EDUFES, 2004.

CHIAVATTA, Maria. A Formação de professores para a Educação Profissional e Tecnológica: perspectiva histórica e desafios contemporâneos. In: I Conferên-cia Nacional de Educação Profissional e Tecnológica. Anais e Deliberações. Brasília: Ministério da Educação, Secretaria de Educação Profissional Tecnológica, 2006.

CORTELAZZO, lolanda B. C. Prática pedagógica, aprendizagem e avaliação em educação a distância. 2 ed. Curitiba: IBPEX, 2009.

COUTINHO, Gustavo L. A Era dos Smartphones: um estudo exploratório sobre o uso dos Smartphones no Brasil. Monografia de Publicidade e Propaganda da Universidade de Brasilia. (2014). Disponível em:

http://bdm.unb.br/bitstream/10483/9405/1/2014_Gustavo LeuzingerCoutinho.pdf. Acesso em 19 jan. 2019.

DEMO, Pedro. Pesquisa; princípio científico e educativo. 6 ed. São Paulo: Cortez, 1998.

GIROUX, Henry A. Os professores como intelectuais. Rumo a uma pedagogia crítica da aprendizagem. Porto Alegre: Artmed, 1997. 
GOMEZ, G. O. Podemos ser mais criativos ao adotar a inovação tecnológica em educação? Uma proposta em comunicação. Revista Matrizes no 1, p.209-216, out. 2007.

GUIMARÃES, Angelo; RIBEIRO, Antonio M. Introdução às tecnologias da informação e da comunicação: tecnologia da informação e da comunicação. Belo Horizonte: UFMG, 2011.

HERNANDEZ, Fernando et al. Aprendendo com as inovações nas escolas. Porto Alegre: Artmed, 2000.

KRONBAUER, Selenir C. G.; SIMIONATO, Margareth F. Formação de Professores. Abordagens Contemporâneas. São Paulo: Paulinas, 2008.

LUBLICK, Ana M. P.; PETRAITS, Rosa A.; LUBLIK, Laima I. Contextos Educacionais por uma educação integral e integradora de saberes. Curitiba: IBPEX, 2011.

MELO, Alessandro. Fundamentos socioculturais da educação. Curitiba: IBPEX, 2011.

MENEZES, Maria A. Currículo, formação e inclusão: alguns implicadores. In: FELDMANN, Marina G. (org.). Formação de professores e escola na contemporaneidade. São Paulo: Senac, 2009.

MESSINA, G. Mudança e inovação educacional: notas para reflexão. Cadernos de Pesquisa. № 114, 2001, p. 225 - 233.

PEREZ, Geraldo. Prática reflexiva do professor de matemática. In: BICUDO, Maria Aparecida V.; BORBA, Marcelo C. (orgs.) Educação matemática: pesquisa em movimento. 2 ed. São Paulo: Cortez, 2005.

POMBO, Olga. Interdisciplinaridade e Integração dos Saberes. Disponível em: <http://www.educ.fc.ul.pt/docentes/opombo/investigacao/porto\%20alegre.pdf> Acesso em: 12 jan. 2019.

ROJO, Roxane. Pedagogia dos Multiletramentos: Diversidade Cultural e de Linguagem na Escola. In: ROJO, Roxane; MOURA, Eduardo (orgs.). Multiletramentos na Escola. São Paulo: Parábola Editorial, 2012.

SAVIANI, Dermeval. Escola e democracia. 32. ed. Campinas, SP: Autores Associados, 1999.

SOUZA, Ricardo A. Aprendizagem em regime tandem: uma alternativa no ensino de línguas estrangeiras on-line. 2 ed. In: RODRIGUES-JUNIOR, Adail S. (org.).

Internet e Ensino: Novos gêneros, outros desafios. Rio de Janeiro: Singular, 2009. 
SUHR, Inge R. F. Teorias do conhecimento pedagógico. Curitiba: IBPEX, 2011.

TARDIF, Maurice. Saberes Docentes \& Formação Profissional. 6 ed. Petrópolis: Vozes, 2002.

TEDESCO, Juan Carlos. O Novo Pacto Educativo. São Paulo: Ática, 2004.

VYGOSTSKY, Luria. Pensamento e Linguagem. São Paulo: Martins Fontes: 2003.

WEBER, Max. Economia e sociedade: fundamentos da sociologia compreensiva. Brasília, DF: Editora Universidade de Brasília: São Paulo: Imprensa Oficial do Estado de São Paulo, 1999.

ZAVAM, Aurea. E-Zine: uma instância da voz dos e-xcluídos. 2 ed. In: RODRIGUES-JUNIOR, Adail S. (org.). Internet e Ensino: Novos gêneros, outros desafios. Rio de Janeiro: Singular, 2009. 